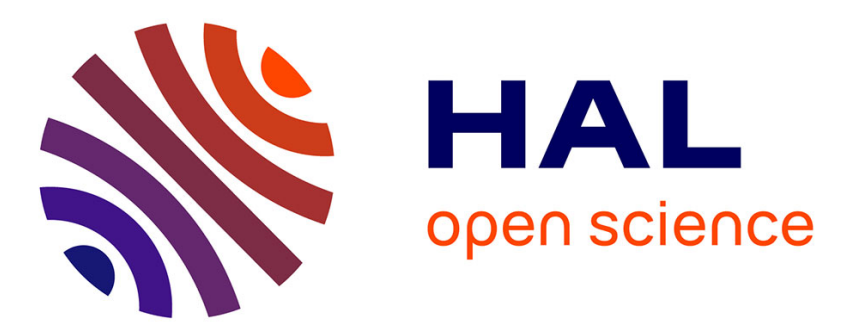

\title{
Estimation of the number of seriously injured road users in France, 2006-2015
}

Emmanuelle Amoros, Grégory Soler, Léa Pascal, Jean-Louis Martin, Amina Ndiaye, Blandine Gadegbeku, B. Laumon

\section{- To cite this version:}

Emmanuelle Amoros, Grégory Soler, Léa Pascal, Jean-Louis Martin, Amina Ndiaye, et al.. Estimation of the number of seriously injured road users in France, 2006-2015. European Congress of Epidemiology, Jul 2018, LYON, France. Elsevier, European Congress of Epidemiology, 66 (Suppl 5), pp.S334, 2018, 10.1016/j.respe.2018.05.258 . hal-02173144v2

\section{HAL Id: hal-02173144 \\ https://hal.science/hal-02173144v2}

Submitted on 26 Aug 2019

HAL is a multi-disciplinary open access archive for the deposit and dissemination of scientific research documents, whether they are published or not. The documents may come from teaching and research institutions in France or abroad, or from public or private research centers.
L'archive ouverte pluridisciplinaire HAL, est destinée au dépôt et à la diffusion de documents scientifiques de niveau recherche, publiés ou non, émanant des établissements d'enseignement et de recherche français ou étrangers, des laboratoires publics ou privés. 


\section{Estimation of the number of seriously injured road users, France 2006-2014}

E. Amoros, G. Soler, L. Pascal, JL Martin, A. Ndiaye, B. Gadegbeku, B. Laumon, UMRESTTE, IFSTTAR France, University of Lyon, France

Request from EU : how many serioulsy injured (MAIS3+) road users ?

\section{Available data}

National Police data : incomplete, biased (least reported $=$ the slightly injured, injured on M2W or bicycle, injured in single-vehicle accident, ...

Rhône road trauma registry: almost complete, unbiased

Based on 250 public and private hospital units: from pre-emergency care

resuscitation, surgery, ... to rehabilitation ; includes hospitalised or only treated at emergency departments.

All injuries coded in AIS (Abbreviated Injury Scale); AIS score: 1=minor severity,

$2=$ moderate, $3=$ serious, $4=$ severe, $5=$ critical, $6=$ beyond treatment

MAIS= Maximum AIS score if multiple injuries. MAIS3+ = seriously injured.

Method

Police and registry data are linked (probabilistic linkage)

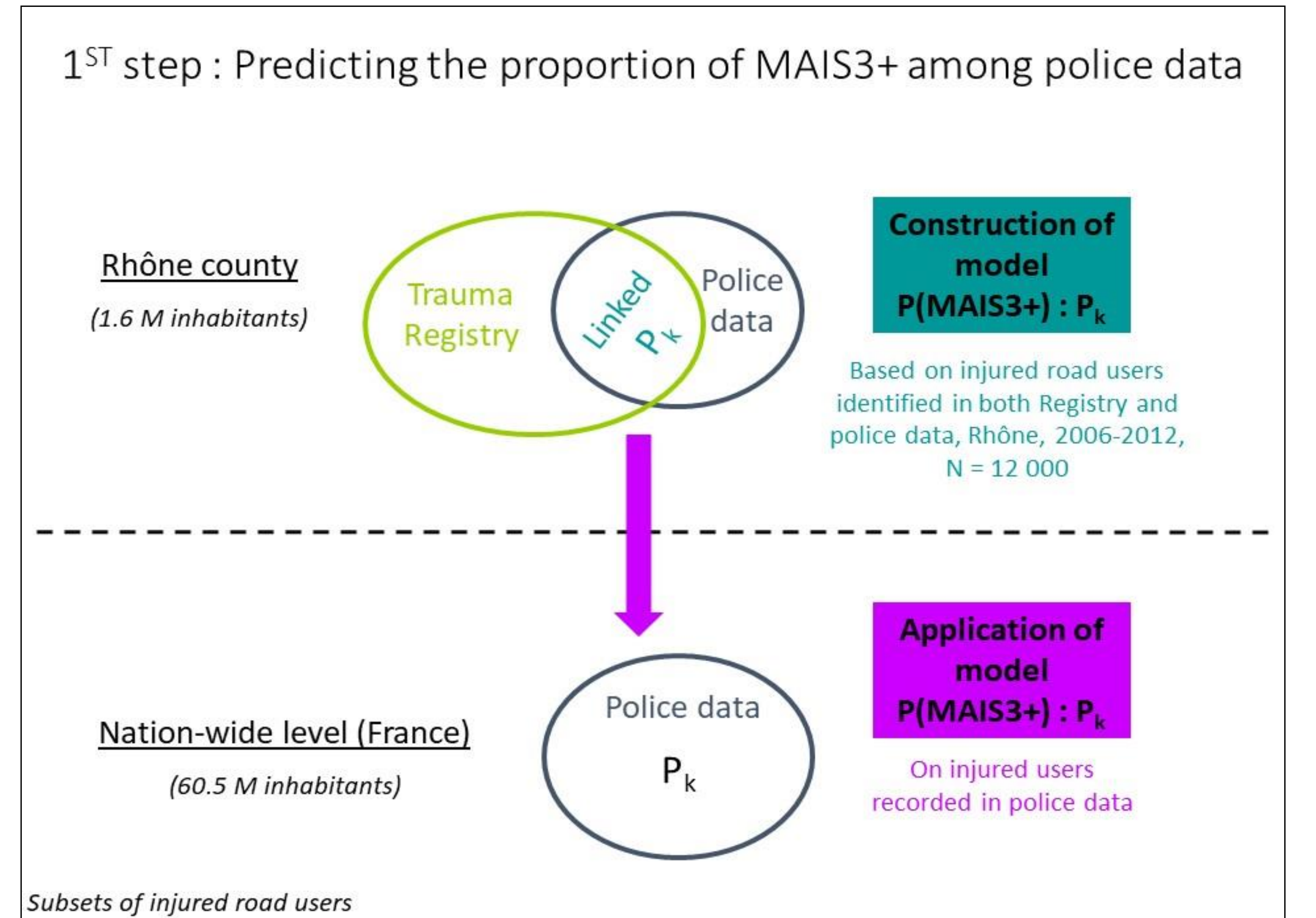

1 st step : predicting the proportion of MAIS3+ among injured, all severities a) Construct multivariate model on Rhône linked data accounting for $k$ factors, influencing MAIS severity = crash severity (fatal or not), hospitalised (yes/no), road user type (car, bicycle...), crash opponent (yes/no), type of crash opponent (car, bicycle...), age, gender, type of police force, in/out of town b) Apply model on national police data.

\section{Results 2014}

291693 injured, all severities (vs. 73048 from police data)

Incidence is $455 / 100000$ inhabitants

24592 seriously (MAIS3+) injured ; incidence is 38.4 /100 000 inhabitants

External validation : Firemen national data :

270000 injured from firemen data in 2012, versus

308000 injured from extrapolated police data (2012)

Number of casualties all severities, by road user type, France, 2006-2012
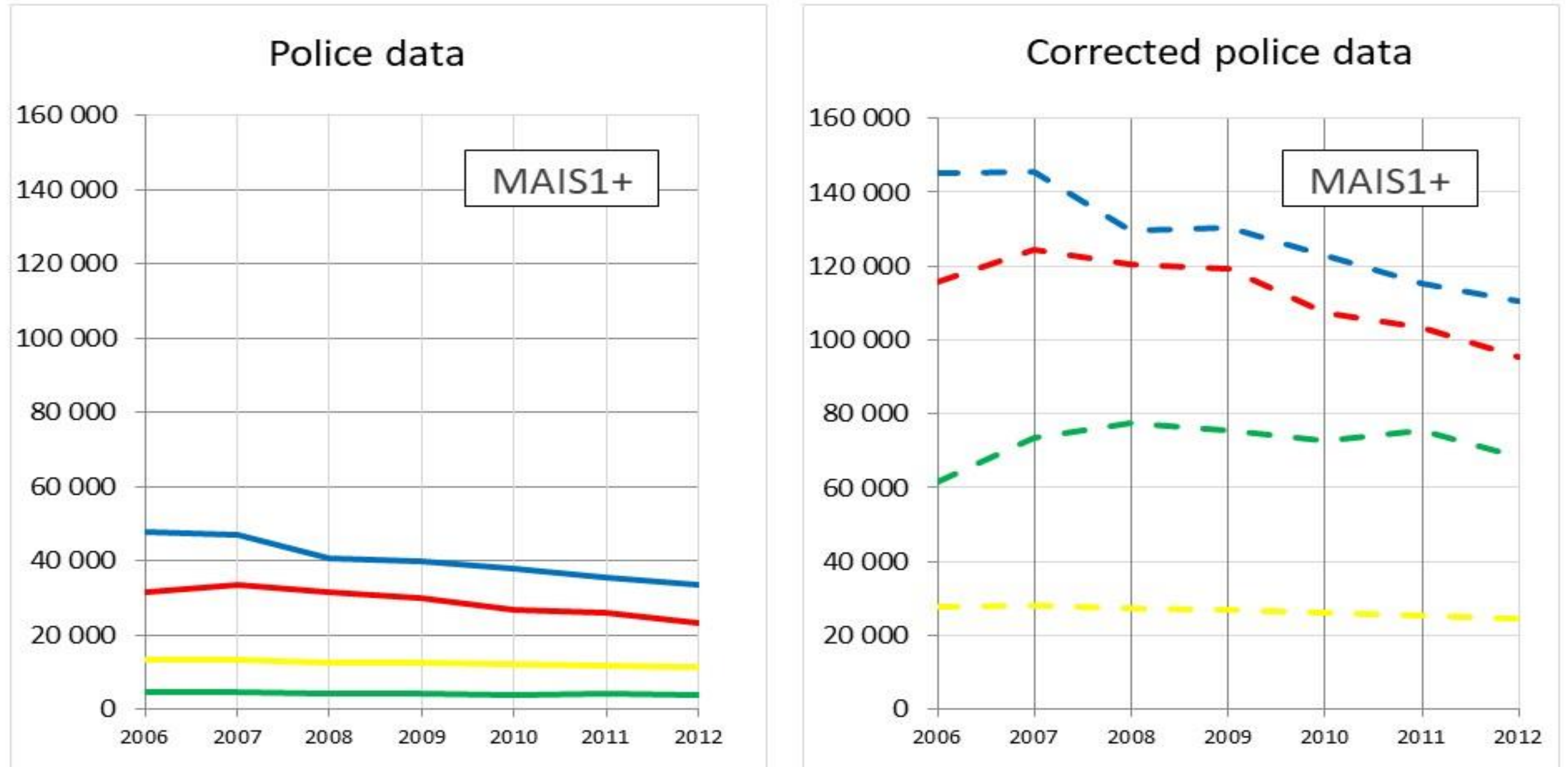

—MTW users —Cyclists — Car occupants — Pedestrians

Correction for under-reporting and biais multiplies the number of injured by 3.6 and leads to more injured cyclists than injured pedestrians.

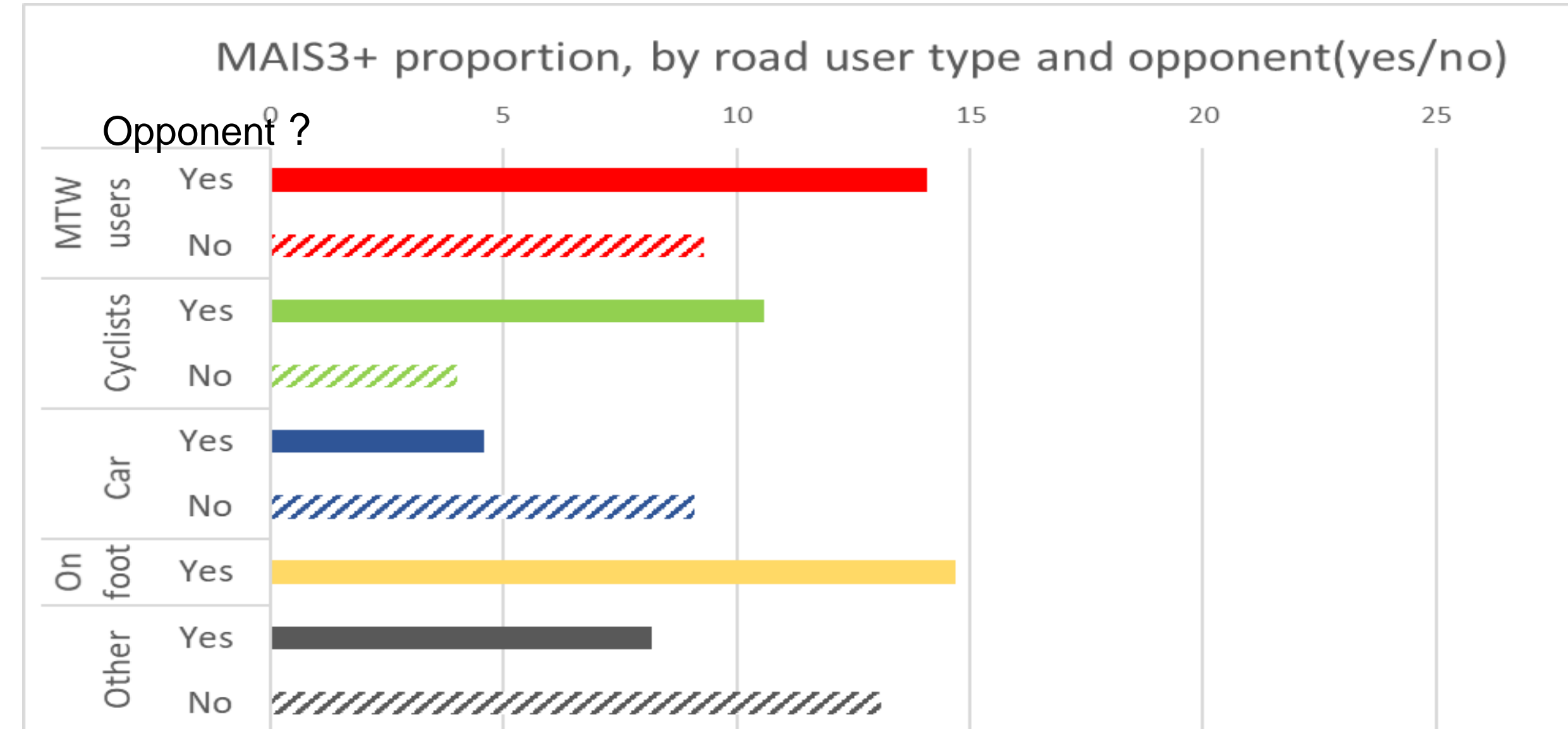

The most seriously injured road users are pedestrians and users of motorised twowheel in a crash with a motorised opponent

Cyclists and users of M2W : less seriously injured in crashes on their own than in Cyclists and users of $\mathrm{M} 2 \mathrm{~W}$ : less seriously injured in crashes
crashes with a crash opponent (motorised most of the times)

crashes with a crash opponent (motorised most of the times) Car occupants and other users : more seriously injured in crashes on their own (mainly loss of control).

Acknowledgments: ARVAC.

Funding: Direction Sécurité Routière, French Interior Ministry Contact: emmanuelle.amoros@ifsttar.fr.
Method (continued)

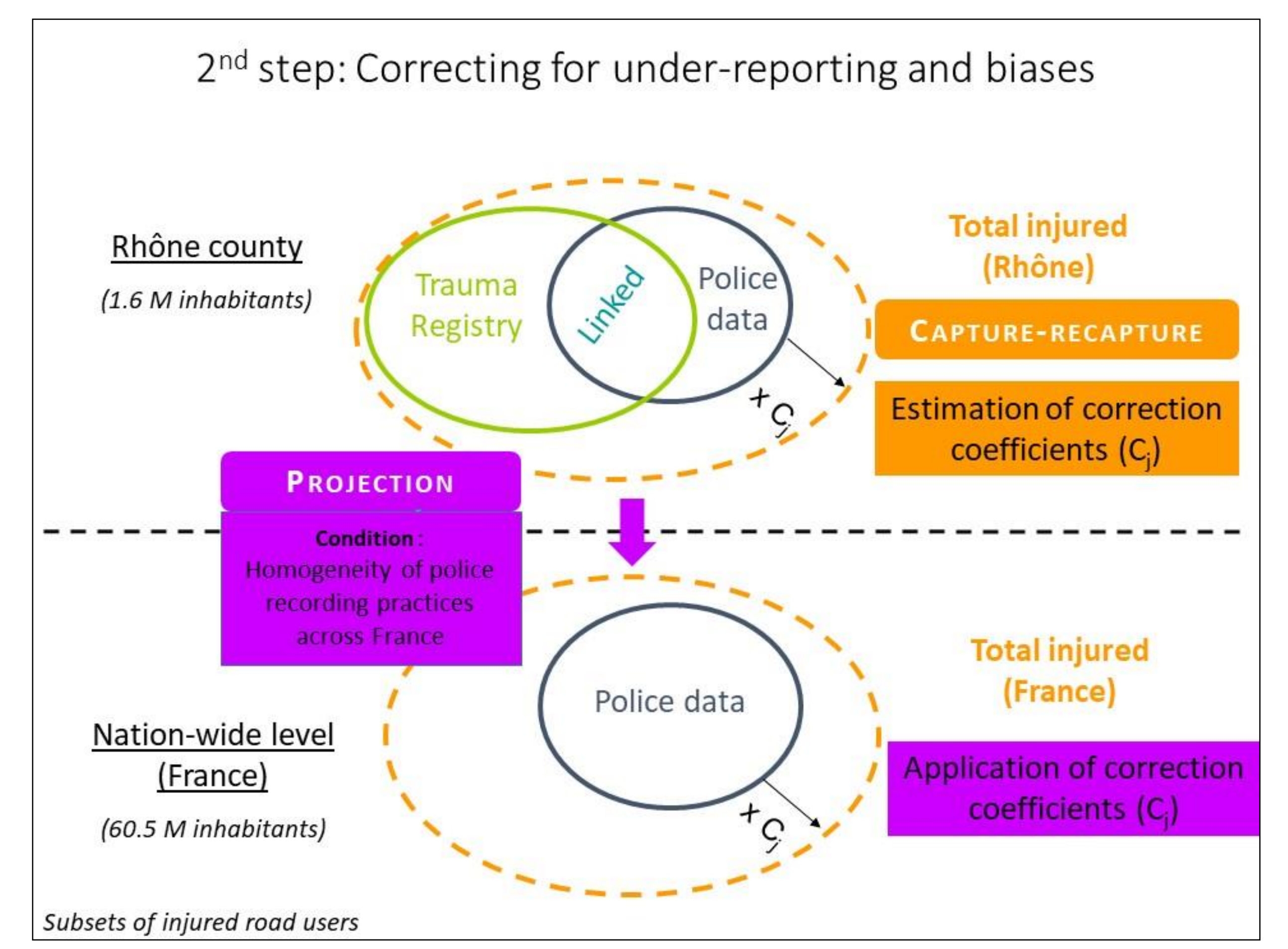

$2^{\text {nd }}$ step : Capture-recapture on the Rhône data

1 st capture $=$ medical registry, $2^{\text {nd }}$ capture $=$ police data

Modelisation to account for factors influencing police reporting: crash severity, user severity (MAIS), hospitalised (yes/no), road user type, single vs multi vehicle crash, type of police force road type

$=>$ total number of injured road users in the Rhône + correction factors for police data (Cj) $=>$ projection: application of correction factors $\mathrm{Cj}$ to national police data (similar to undirect standardisation, on age and sex in general)

Results

Number of serious casualties, by road user type, France, 2006-2012

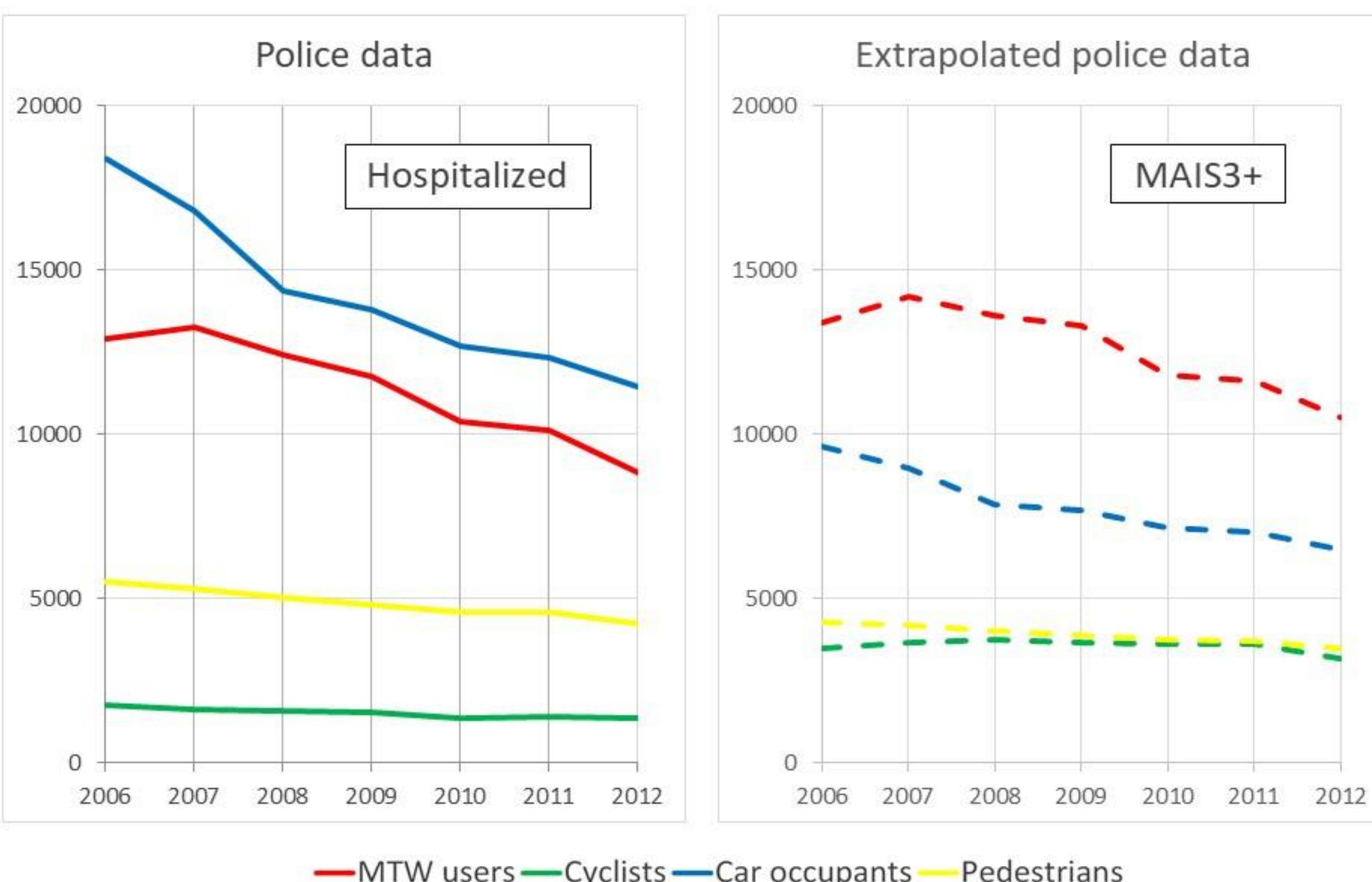

Correction for police reporting biases leads to more seriously injured M2TW users than car occupants (while they respectively represent $2 \%$ and $70 \%$ of traveled kilometres ; National Travel survey, 2008-2009). It also leads to seriously injured cyclists being as numerous as seriously injured pedestrians (while they respectively account for $2 \%$ and $23 \%$ of trips).

Frequencies of MAIS1+ injured road users, France, 2006-2012

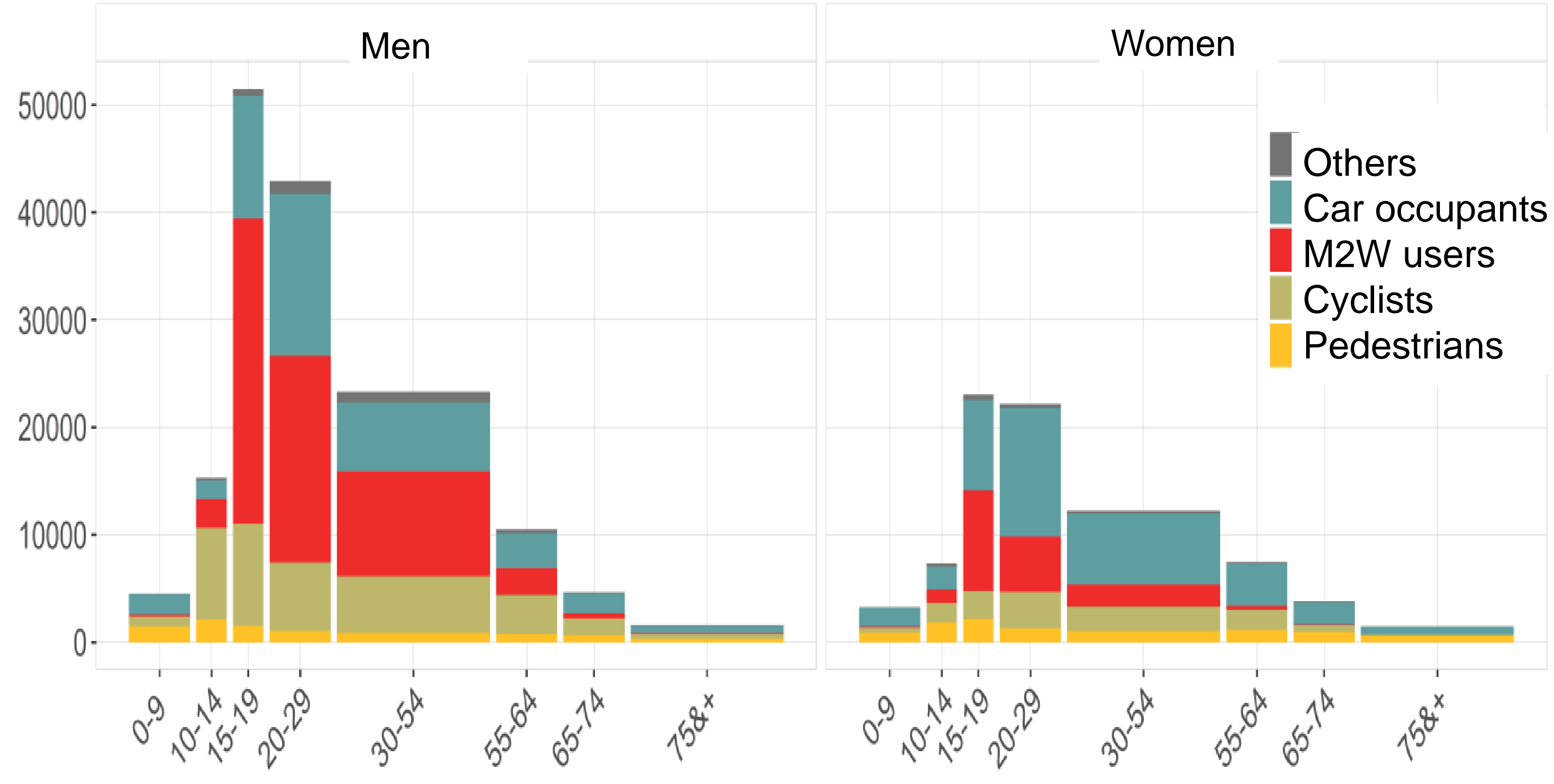

Sex-ratio is 1.9 for injured road users while they travel the same (slightly more kilometers for men, but slightly more trips for women). The main difference is on injured cyclists and injured users of M2W (motorised two wheel)

Sex-ratio is 4.3 for M2W users, 2.6 for cyclists, 1.1 for a car occupants, 0.9 for pedestrians and 3.0 for others. It is even more marked for MAIS3+ casualties: 7.2 for M2W users, 5.3 for cyclists, 1.7 for car occupants, 1.0 for pedestrians and 4.5 for others.

Proportion of seriously injured increases with age, but with a peak at 16-19 years old (not shown).

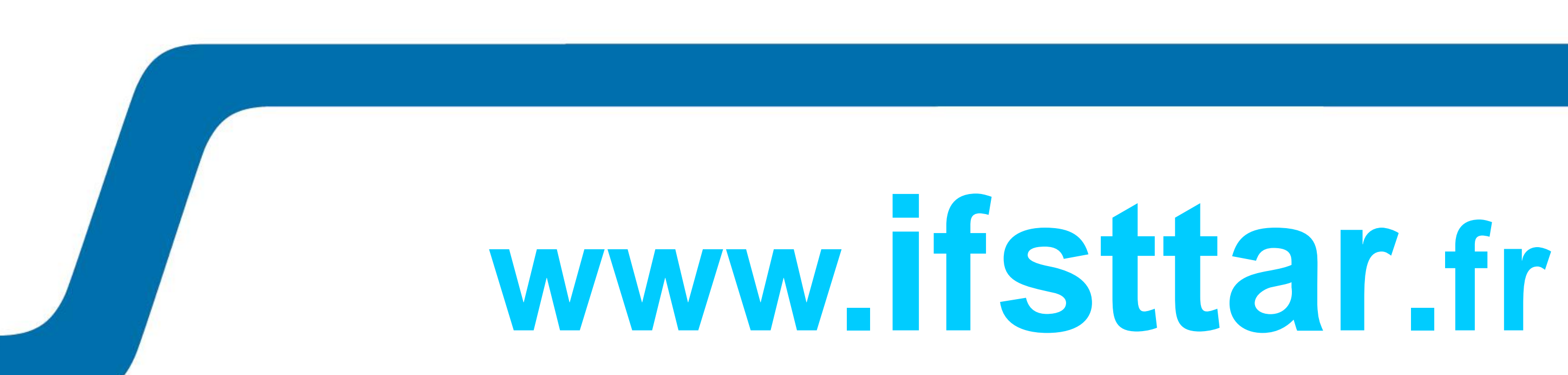

